\title{
Adenosine Induces Inositol 1,4,5-Trisphosphate Receptor-Mediated Mobilization of Intracellular Calcium Stores in Basal Forebrain Cholinergic Neurons
}

\author{
Radhika Basheer, ${ }^{1}$ Elda Arrigoni, ${ }^{2}$ Hemant S. Thatte, ${ }^{3}$ Robert W. Greene, ${ }^{4}$ Indu S. Ambudkar, ${ }^{5}$ and \\ Robert W. McCarley ${ }^{1}$
}

Departments of ${ }^{1}$ Psychiatry, ${ }^{2}$ Neurology, and ${ }^{3}$ Surgery, Harvard Medical School, Veterans Affairs Medical Center, West Roxbury, Massachusetts 02132, ${ }^{4}$ Department of Psychiatry, University of Texas Southwestern Medical Center and Dallas Veterans Affairs Medical Center, Dallas, Texas 75390, and 5 Secretory Physiology Section, Gene Therapy and Therapeutics Branch, National Institute of Dental and Craniofacial Research, National Institutes of Health, Bethesda, Maryland 20892

In the cholinergic basal forebrain, we found previously that the extracellular adenosine concentration increase that accompanies sleep deprivation, acting via the $A_{1}$ receptor, led to activation of the transcription factor nuclear factor- $\kappa \mathrm{B}$ and to the upregulation of $A_{1}$ adenosine receptor mRNA. We thus began to examine intracellular signaling mechanisms. We report here that adenosine, acting in a dose-dependent manner and predominantly via $A_{1}$ receptors, stimulated $\mathrm{IP}_{3}$ receptor-regulated calcium release from intracellular stores. To the best of our knowledge, this calcium signaling pathway effect is a novel action of the $G_{i}$-coupled $A_{1}$ adenosine receptor in neurons. Moreover, this calcium mobilization was not seen at all in noncholinergic neurons but was present in a large proportion of cholinergic neurons. These data suggest a potential role for a calcium-signaling pathway in adenosine-induced long-term effects of sleep deprivation and a key role for cholinergic neurons in this process.

Key words: adenosine; cholinergic basal forebrain; $A_{1}$ adenosine receptor; intracellular calcium mobilization; inositol 1,4,5trisphosphate receptor activation; sleep deprivation
There is now considerable evidence that adenosine, acting in the basal forebrain $(\mathrm{BF})$, is a homeostatic sleep factor regulating the increased propensity to sleep after an increased duration of wakefulness (Porkka-Heiskanen et al., 1997; Basheer et al., 1999, 2000). There is also a considerable body of evidence about the immediate effects of adenosine on postsynaptic membrane ionic mechanisms. Adenosine, via the $\mathrm{A}_{1}$ receptor, activates an inwardly rectifying potassium current and blocks the hyperpolarizing current, thereby causing hyperpolarization of neurons (Rainnie et al., 1994; for review, see Haas and Selbach, 2000).

In contrast, very little is known in the brain, and nothing in the $\mathrm{BF}$, about the long-term effects of adenosine that may be mediated by prolonged receptor activation and second messengermediated intracellular mechanisms. This may be important not only from the standpoint of the intrinsic value of increased cellular and biological knowledge but also for the possible behavioral consequences of such actions. For example, sleep restriction over several days produces progressive, additive effects such as decreased neurobehavioral alertness, decreased verbal learning, and changes in metabolic, endocrine, and immune functions, often referred to as "sleep debt" (Dinges et al., 1995, 1997; Spiegel et al., 1999; Drummond et al., 2000). Such effects might

Received March 25, 2002; revised May 30, 2002; accepted June 3, 2002.

This work was supported by National Institute of Mental Health Grant MH 39683 and awards from the Veterans Administration to R.W.M. and from the Sleep Medicine Education Research Foundation to R.B. We thank Dr. Aldebaran M. Hofer for providing HEK 293 cells and helpf ul suggestions and Dr. Matthew Palmer for designing the slice chamber.

Correspondence should be addressed to Dr. Robert W. McCarley, Harvard Medical School and Boston Veterans Affairs HealthCare System, Psychiatry, 116A, 940 Belmont Street, Brockton, MA 02301. E-mail: Robert_mccarley@hms.harvard.edu. Copyright (C) 2002 Society for Neuroscience $0270-6474 / 02 / 227680-07 \$ 15.00 / 0$ stem from adenosine receptor-mediated activation of secondmessenger pathways that ultimately lead to altered transcription of genes coding for proteins that are important in the long-term effects of sleep deprivation.

The BF cholinergic zone has cells with several neurotransmitter phenotypes, including cholinergic, GABAergic, glutamatergic, and peptidergic (Gritti et al., 1993; Zaborszky et al., 1999; Semba, 2000). It has not been clear whether one or more of these cell types is associated with a distinctive second-messenger profile and hence might be associated with a distinctive functional role. The $A_{1}$ receptor-mediated immediate ionic effects do not appear to discriminate between cell types, because they occur in cholinergic and noncholinergic neurons, at least in the laterodorsal tegmental nucleus (Rainnie et al., 1994).

Our previous identification of increased nuclear factor (NF)- $\kappa \mathrm{B}$ DNA binding as a consequence of sleep deprivation and an effect mediated by the $A_{1}$ receptor (Basheer et al., 2001a) suggested that we should first look at the possible signaling pathways coupling the $A_{1}$ receptor to activation of this transcription factor. Several $\mathrm{G}_{\mathrm{i} / \mathrm{o}}$-coupled receptors have been shown to be capable of "dual signaling" [i.e., inhibition of adenylate cyclase and stimulation of phospholipase C (PLC)] (Gudermann et al., 1996, 1997). In smooth muscle cells and astrocytes, the $A_{1}$ adenosine receptor has been shown to be capable of dual signaling (Gerwins and Fredholm, 1992; Biber et al., 1997). Activation of the PLC pathway is capable of activating protein kinase $\mathrm{C}$ (PKC) by $\mathrm{IP}_{3}$-mediated mobilization of internal calcium (Nishizuka, 1992; Berridge, 1998). Finally, PKC-mediated phosphorylation of the inhibitor $\mathrm{I}-\kappa \mathrm{B}$ and subsequent release and nuclear translocation of $\mathrm{NF}-\kappa \mathrm{B}$ are very well characterized in $\mathrm{T}$ lymphocytes (McKinsey et al., 1997). However, $A_{1}$ adenosine receptor- 
mediated activation of the PLC pathway and mobilization of intracellular calcium have not been reported in neurons, although there are reports of transient changes in intracellular calcium that can act as a part of a signal cascade coupling receptor activation to the nuclear events regulating transcription (Hardingham and Bading, 1999).

We thus chose to examine the intracellular signal transduction cascade activated by adenosine. More specifically, we investigated the following possible cascade components: whether adenosine was capable of inducing an increase in cytosolic calcium; the intracellular or extracellular source of this calcium; the involvement of the endoplasmic reticulum $(E R) I_{3}$ receptor $\left(I P_{3} R\right)$ versus the ryanodine receptor (RyR); and the adenosine receptor type(s) mediating these effects.

We report here that in the $\mathrm{BF}$, adenosine acts to mobilize cytosolic calcium in a dose-dependent manner, that this mobilization is mediated by the ER $\mathrm{IP}_{3} \mathrm{R}$, and that these actions occur primarily through the $\mathrm{A}_{1}$ adenosine receptor. Moreover, these events occur only in cholinergic neurons.

\section{MATERIALS AND METHODS}

Experimental animals. Male Long-Evans rats (350-300 gm) were housed in a $12 \mathrm{hr}$ light/dark cycle (lights on 7:00 A.M. to 7:00 P.M.) at a constant temperature $\left(23^{\circ} \mathrm{C}\right)$ with access to food and water ad libitum.

Acute brain slice preparation and loading of calcium orange dye. The animals were decapitated after isoflurane-induced anesthesia, and their brains were rapidly removed. Coronal sections $(200 \mu \mathrm{m}$ thick) were cut with a vibratome (TPI series 3000 ; St. Louis, MO) at $4^{\circ} \mathrm{C}$ in artificial CSF (aCSF; in mm: $124 \mathrm{NaCl}, 2 \mathrm{KCl}, 3 \mathrm{KH}_{2} \mathrm{PO}_{4}, 1.3 \mathrm{MgCl}_{2}, 2.5 \mathrm{CaCl}_{2}, 26$ $\mathrm{NaCO}_{3}$, and 10 glucose, $\mathrm{pH} 7.35 ; 315-320$ mOsm when gassed with $95 \%$ $\mathrm{O}_{2}$ and $5 \% \mathrm{CO}_{2}$ ). Three slices per animal [bregma coordinates from 0 to 0.6 (Paxinos and Watson, 1998), including the horizontal and diagonal band (HDB)-substantia innominata (SI)-magnocellular preoptic area (MCPO) region of the $\mathrm{BF}$ ] were collected. The slices were hemisected and mounted on Parafilm. Calcium orange dye in aCSF $(1 \mathrm{ml} ; 10 \mu \mathrm{M}$ final concentration) was layered over the brain slice and incubated for 1 $\mathrm{hr}$ at $21^{\circ} \mathrm{C}$; slices were washed and used for drug treatment and imaging in carboxygenated buffer. Uniform loading of the dye was evident because of the visible levels of basal fluorescence of calcium orange in resting (unstimulated) neurons. Tetrodotoxin $(1 \mu \mathrm{M})$ in the buffer was used for all of the experiments to ensure the postsynaptic nature of the effects. The real-time change in intracellular calcium fluorescence was measured every $1.37 \mathrm{sec}$ to determine the time needed for maximum effect.

To test the effect of fixing the slices in neutralized formalin on the intensity of calcium orange, we performed a time-course experiment in which calcium orange-loaded slices (four slices per time point from four rats) were treated with $100 \mu \mathrm{M}$ adenosine for $0,10,20,30,40,60$, and 100 sec and fixed in formalin at the end of each time point before the fluorescence intensity was measured. The process of fixing did not have any effect on the increase in fluorescence intensity in response to adenosine. The time course of fluorescence intensity increase in fixed slices followed the same pattern that was observed in real-time measurements (Fig. 1A,B).

Drugs. The sources of the drugs used were as follows: adenosine, the RyR blocker 1,1'-diheptyl-4-4'-bipyridinium (DHBP), the $\mathrm{IP}_{3} \mathrm{R}$ blocker xestospongin $\mathrm{C}$, and 2-aminoethoxydiphenylborane (2APB) were obtained from Calbiochem (La Jolla, CA). The $\mathrm{A}_{1}$ agonist $N^{6}$-cyclo-hexyladenosine (CHA), $\mathrm{A}_{1}$ antagonist 8-cyclopentyl-1,3-dimethylxanthine (CPT), $\mathrm{A}_{2}$ agonist $N^{6}$-[2-(3,5-dimethoxyphenyl)-2-(methylphenyl)ethyl]adenosine (DPMA), $\mathrm{A}_{3}$ agonist $N^{6}$-(4-aminobenzyl)-9-[5(methylcarbonyl)- $\beta$-D-ribof uranosyl]adenine (AB-MECA), and $\mathrm{A}_{3}$ antagonist 3-ethyl-5-benzyl-2-methyl-4-phenylethynyl-dihydropyridinedicarboxylate (MRS1191) were obtained from Sigma-RBI (St. Louis, $\mathrm{MO})$.

Immunofluorescence labeling. Coronal sections that were used for calcium imaging were fixed in buffered formalin, $\mathrm{pH}$ 7.2, permeabilized with $0.5 \%$ TritonX-100in PBS under constant shaking for $2 \mathrm{hr}$, and subsequently treated with specific ChAT antibody (AB 144; goat antibody; Chemicon, Temecula, CA) used at a dilution of 1:4000. FITC-conjugated secondary antibody (anti-goat antibody; 1:100 dilution; Chemicon) was
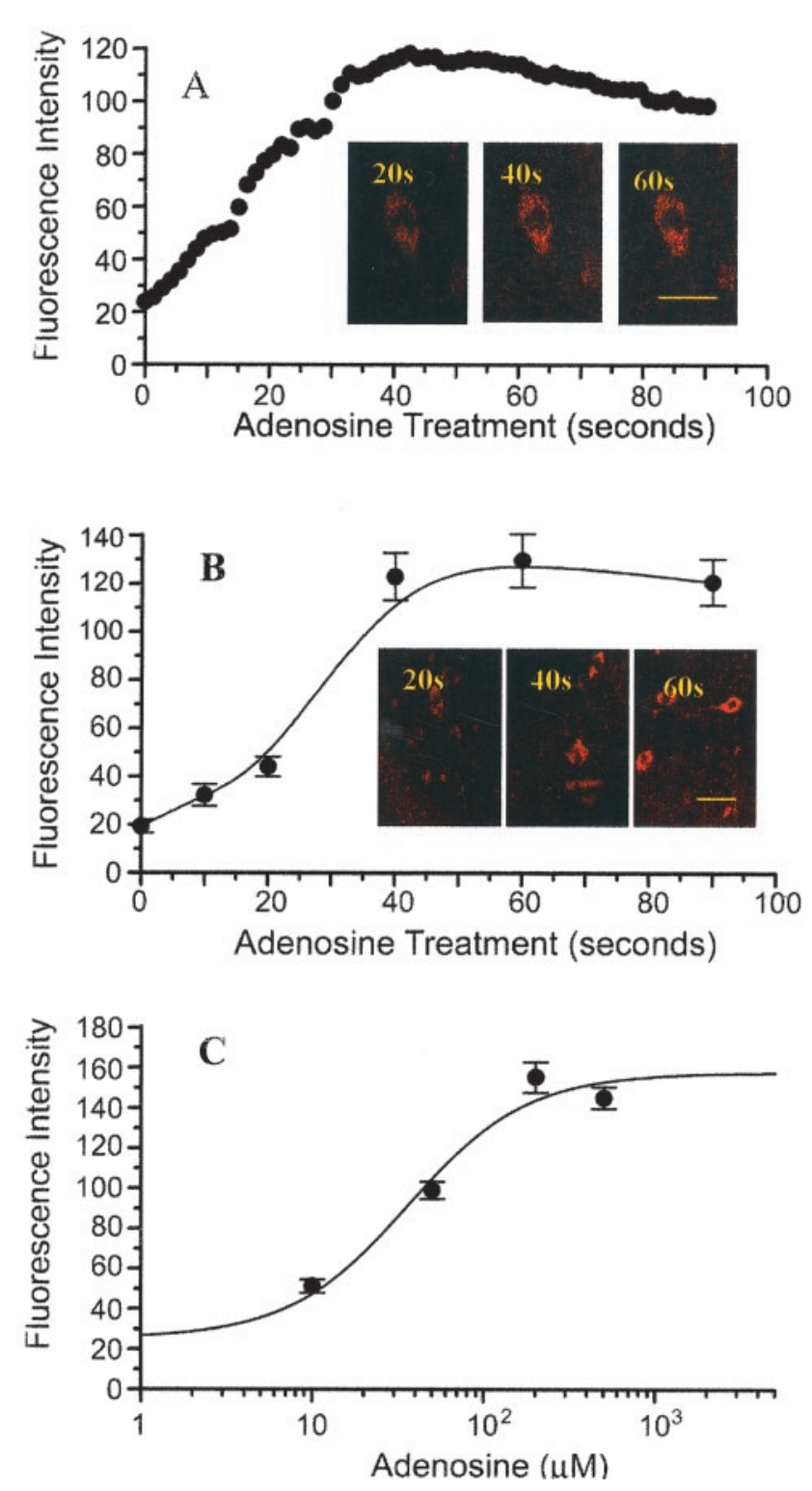

Figure 1. Effect of adenosine on the intracellular calcium of BF neurons. $A$, Typical time course of calcium increase, measured as increase in calcium orange fluorescence in a live neuron in an acute slice after treatment with $100 \mu \mathrm{M}$ adenosine (two photon microscope measurements every $1.37 \mathrm{sec}$ ). Insets, Photomicrographs of a cell at the indicated time points. Note that the maximal fluorescence is achieved by $45-60 \mathrm{sec}$, and note the size of the neuron. Scale bar, $25 \mu \mathrm{m}$. B, Time course of fluorescence of neurons in slices fixed at various times after adenosine treatment $(100 \mu \mathrm{M})$. Insets, Photomicrographs of neurons in slices fixed at the indicated time points. Note the close correspondence to the time course of fluorescence in an unfixed neuron $(A)$ and the sizes of the neurons. Scale bar, $50 \mu \mathrm{m}$. $C$, Adenosine concentration-response curve: adenosine concentrations and mean \pm SEM fluorescence are shown $(n=$ 11 neurons per point). Note that the maximum response is achieved at 100 $\mu \mathrm{M}$ adenosine, the concentration chosen for other experiments.

used to visualize ChAT-positive neurons. Samples were imaged by multiphoton microscopy.

Multiphoton microscopy for intracellular calcium imaging. A Bio-Rad (Hercules, CA) MRC 1024ES Multiphoton Imaging system coupled with a mode-locked Spectra-Physics (Fremont, CA) tunable Tsunamisapphire laser system (pulse duration, $<80 \mathrm{fsec}$;repetition rate, $82 \mathrm{MHz}$ ) and a Zeiss (Oberkochen, Germany) Axiovert S100 inverted microscope equipped with a high-quality water immersion objective (40×; 1.2 numerical aperture) was used for quantitative fluorescence imaging of 
samples in epifluorescence mode. Multiphoton excitation was based on the principle that a fluorophore can absorb two or more photons essentially simultaneously and thereby undergo a transition to an excited state (Denk et al., 1995). Labeled neurons in the brain sections were identified by XYZ scanning, generally at depths of $30-170 \mu \mathrm{m}$. The $512 \times 512$ pixel images were collected in a direct detection configuration at a pixel resolution of $0.484 \mu \mathrm{m}$ with a Kalman 3 collection filter. Multiple labeled images were acquired in separate channels using narrow bandpass filters to restrict the emission wavelength and thus avoid bleed-through of aberrant fluorescence. Images were reconstructed and processed using Bio-Rad LaserSharp and Metamorph (Universal Imaging, West Chester, PA) software. The data are presented as the average of at least three blinded experiments performed on different days.

\section{RESULTS}

\section{Adenosine mediates cytosolic calcium increase in a time- and concentration-dependent manner}

To investigate the effect of adenosine on the intracellular calcium response, brain slices were loaded with calcium orange, a calciumsensitive fluorescent dye used previously in slices (Duffy and MacVicar, 1996). The temporal kinetics of the adenosinemediated calcium response was examined in 18 individual neurons $(n=3$ rats; three slices per rat) in real time (Fig. $1 A)$. The temporal profile of adenosine-mediated calcium mobilization after $0,10,20,30,40,60$, and $100 \mathrm{sec}$ of adenosine treatment (11-15 neurons per time point) was examined by measuring the fluorescence intensity after fixing the slices (four slices per time point from four rats) at the end of each time point (see Materials and Methods) (Fig. 1B). Although fixing with neutralized formalin increased the overall intensity of the fluorescence in slices, the net change (cytosolic minus background fluorescence) was found to be comparable with that observed in living neurons in real time. Similar results were obtained in calcium orange-loaded, cultured human embryonic kidney (HEK) 293 cells, in which cytosolic calcium fluorescence intensity remained stable without any leak into the medium after fixation with formalin (data not shown). In both cases (i.e., with or without fixing), the maximal (fourfold to sixfold) increase in calcium orange fluorescence was attained by 45-60 sec after adenosine treatment (Fig. 1A,B). Consequently, this time period was chosen for adenosine treatment in the rest of our experiments. As shown in Figure $1 C$, the intracellular calcium increased in a dose-dependent manner with increasing concentrations of adenosine, reaching a maximal effect at $100 \mu \mathrm{M}$. Consequently, all of the experiments described below were performed using $100 \mu \mathrm{M}$ adenosine for $60 \mathrm{sec}$.

\section{Adenosine-mediated cytosolic calcium increase was selective to cholinergic neurons}

Interestingly, the calcium mobilization induced by adenosine in brain slices was limited to a selective subpopulation of neurons that were $\sim 25-35 \mu \mathrm{m}$ in size and located in the cholinergic portion of the BF region, which includes the HDB, the SI, and the MCPO. The observation that only a limited population of cells showed calcium mobilization with adenosine treatment was intriguing. To rule out potential artifacts caused by differential loading of the dye calcium orange in a specific cell type, we examined mobilization of intracellular calcium with thapsigargin (50 $\mu \mathrm{M}$ for $60 \mathrm{sec}$ ), an intracellular calcium pump inhibitor that is known to release calcium from internal stores in all cell types. Subsequent immunolabeling for ChAT showed that the thapsigargin-mediated increase in calcium orange fluorescence was seen in both cholinergic and noncholinergic cells (Fig. 2, right). In contrast, only those neurons with an increase in calcium orange fluorescence in response to adenosine were ChAT-

\section{Adenosine}
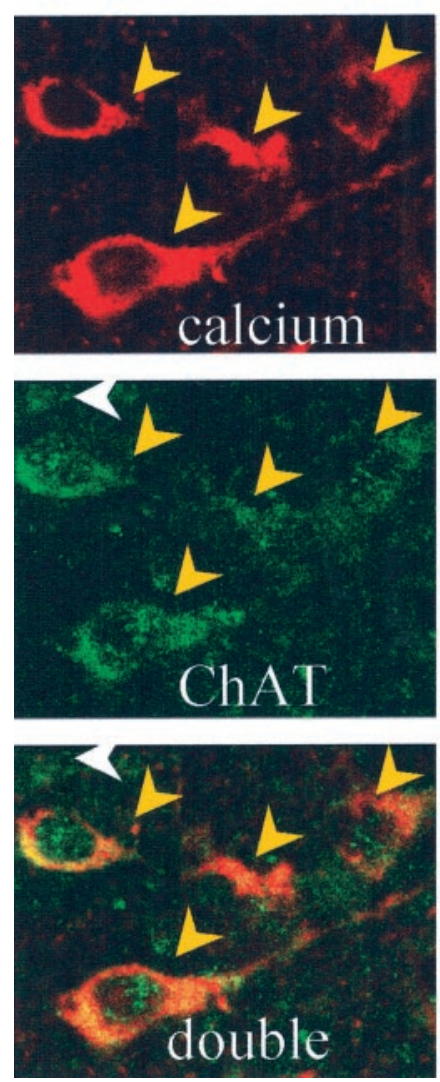

Thapsigargin
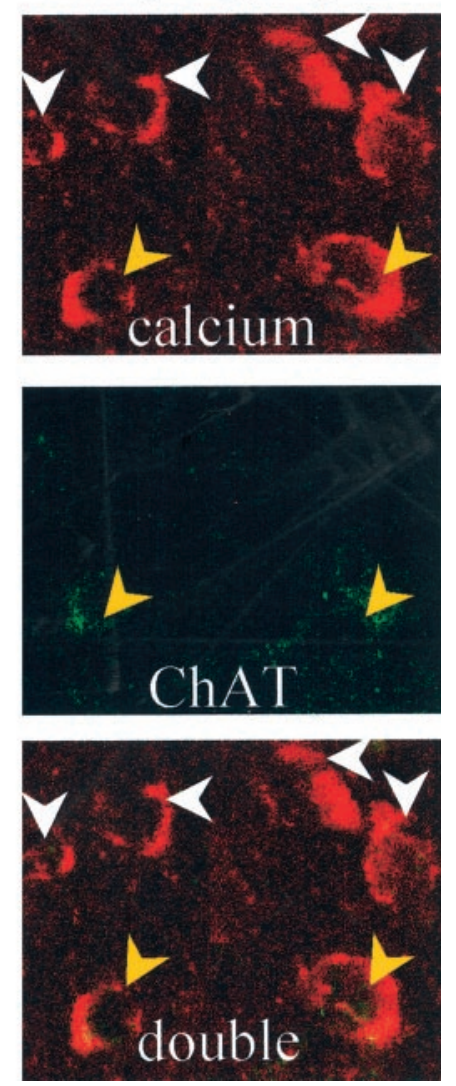

Figure 2. Adenosine-induced cytosolic calcium increase was seen only in cholinergic neurons of the BF. Left column, Effect of adenosine $(60 \mathrm{sec})$ treatment. Right column, Effects of thapsigargin $(60 \mathrm{sec})$ treatment. Top, The calcium orange fluorescence retained in the neurons after immunolabeling for ChAT. Middle, Immunolabeling of the same neurons for ChAT, detected using FITC-conjugated secondary antibody. Bottom, Overlay showing double fluorescence. Note the presence of calcium fluorescence primarily in cholinergic neurons with adenosine (yellow arrowhead). One cholinergic neuron in $A$ (white arrowhead) does not show calcium orange fluorescence. Calcium orange fluorescence is increased in thapsigargin-treated slices $(B)$ in both cholinergic ( yellow arrowhead) and noncholinergic (white arrowhead) cells. Images were acquired separately in each channel (dual-scan mode) to eliminate the possibility of signal bleed-over from one channel to another.

positive (Fig. 2, left). In this analysis, a total of 129 ChAT-positive neurons (average size, $31.7 \pm 2.9 \mu \mathrm{m}$ ) in the HDB-SI-MCPO area of the $\mathrm{BF}$ were examined (seven slices). Of these, 83 neurons $(64.3 \%)$ showed an adenosine-mediated increase in fluorescence, whereas the remaining $46(35.7 \%)$ did not show an increase in fluorescence in response to adenosine. The latter appeared similar in fluorescence to ChAT-positive neurons from control slices that were loaded with the fluorescent dye but not treated with adenosine.

\section{An $A_{1}$-selective agonist largely mimicked the pattern of adenosine response}

The increase in intracellular calcium in response to adenosine (100 $\mu \mathrm{M} ; n=51)$ was measured in individual neurons in slices, as were the responses to the $\mathrm{A}_{1}$ receptor-selective agonist CHA (100 nM; $n=22)$, the $\mathrm{A}_{2}$-selective agonist DPMA $(100 \mathrm{nM} ; n=11)$, and the $\mathrm{A}_{3}$-selective agonist AB-MECA (10 nM; $n=33$ ) (Fig. 


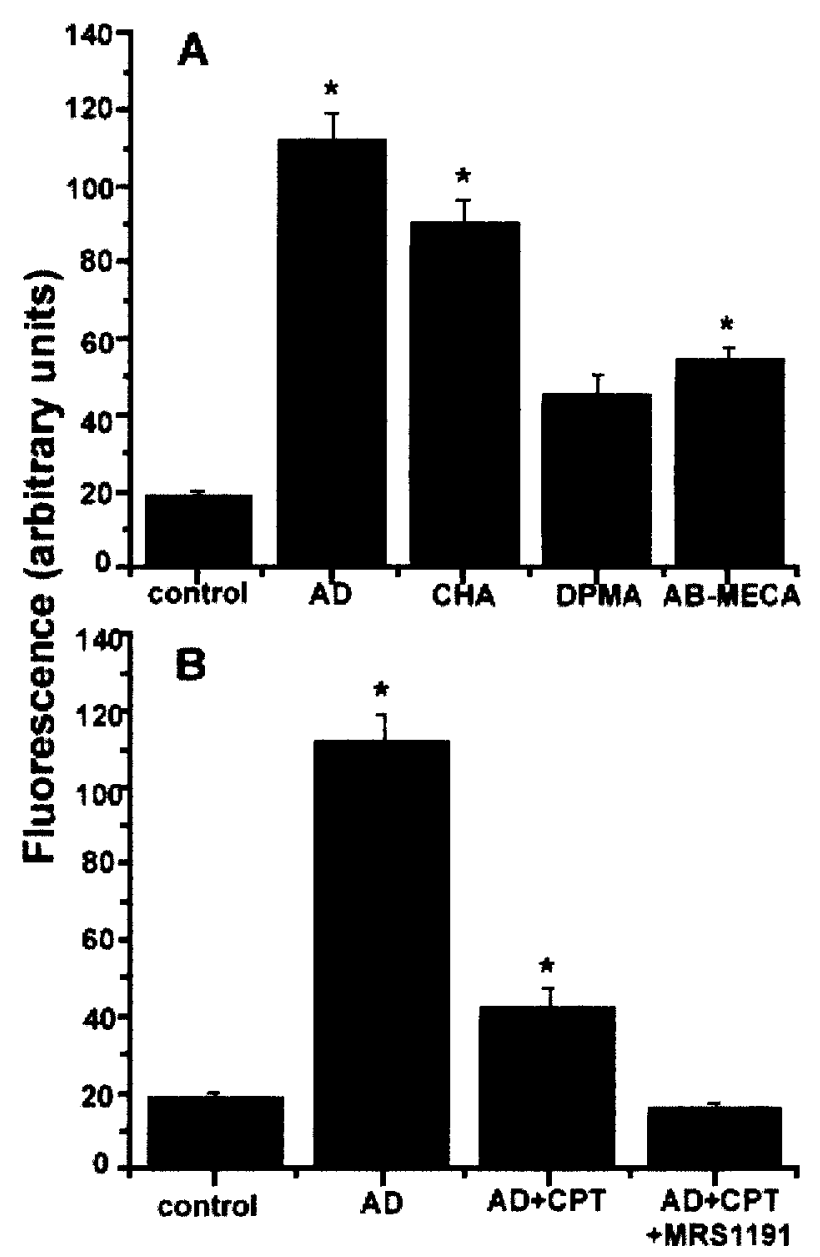

Figure 3. Cytosolic calcium increase in response to different adenosine $(A D)$ receptor agonists: $A$, A significant increase in cytosolic calcium fluorescence was observed in response to adenosine. A similar response was obtained by treatment with the $\mathrm{A}_{1}$ agonist $\mathrm{CHA}$ compared with controls $(p<0.01)$. There was a twofold increase in cytosolic calcium fluorescence with treatment with the $\mathrm{A}_{3}$ agonist AB-MECA versus controls $(p<0.05)$, whereas the $\mathrm{A}_{2}$ agonist DPMA had no significant effect. $B$, The effect of adenosine was significantly but partially blocked by pretreatment of slices with the $\mathrm{A}_{1}$-selective antagonist CPT (significantly lower than adenosine treatments but higher than controls; $p<0.05$ ). However, combined use of $\mathrm{CPT}$ and the $\mathrm{A}_{3}$-selective antagonist MRS1191 rendered the adenosine response not significantly different from controls. The asterisks describe a significant difference when compared with controls.

$3 A$ ). At these concentrations, these agonists have been shown to have relatively high selectivity for their respective receptor subtypes (Klotz, 2000). A Kruskal-Wallis one-way ANOVA showed significant differences among the treatment groups $(\mathrm{H}=115.054$; $\mathrm{df}=4 ; p<0.001)$. Post hoc analysis (Dunn's method) showed a significant increase $(p<0.05)$ in cytosolic calcium with adenosine, CHA, or AB-MECA treatment compared with controls (nonstimulated basal-level fluorescence; $n=45$ ). The observed fivefold increase in fluorescence with adenosine treatment was closely matched by application of the $\mathrm{A}_{1}$-selective agonist CHA. The $\mathrm{A}_{3}$-selective agonist induced only a twofold increase in fluorescence compared with controls. The fluorescence in the cells treated with the $\mathrm{A}_{2}$-selective agonist DPMA was not significantly different from controls.

Figure $3 B$ shows that although the effect of adenosine was not blocked completely, it was primarily blocked by pretreatment of

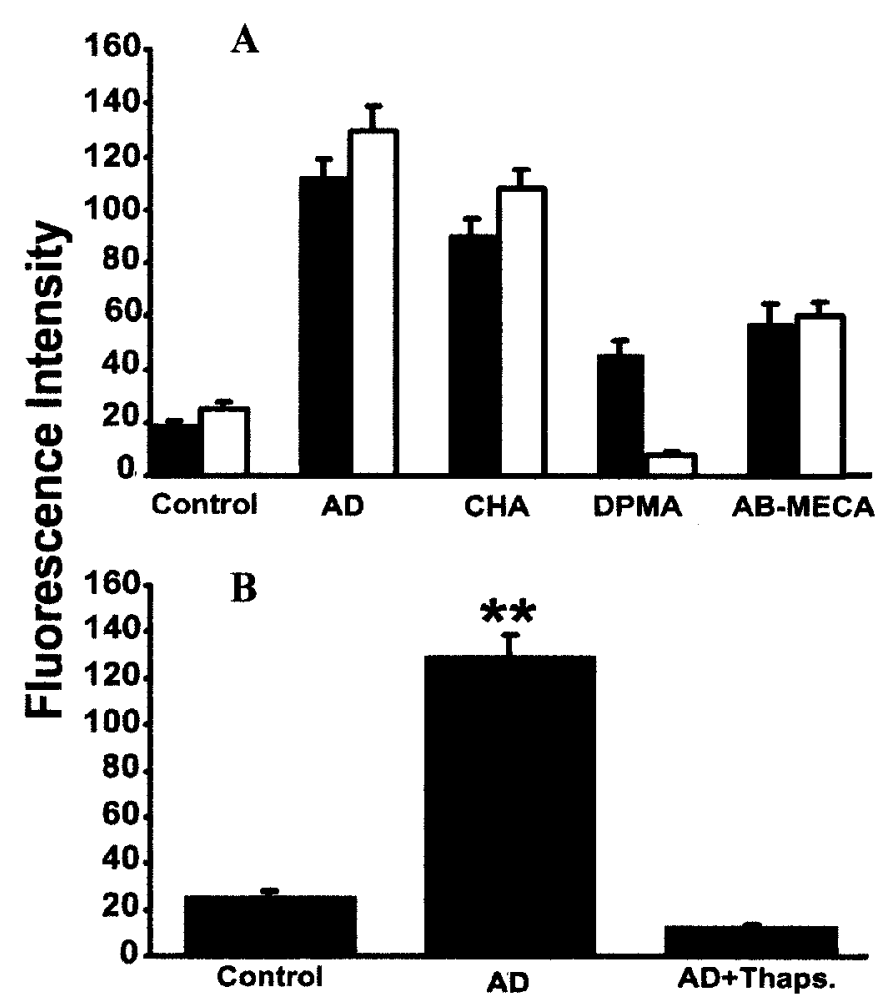

Figure 4. The adenosine $(A D)$-induced cytosolic increase in calcium is independent of calcium in the external medium. $A$, The changes in cytosolic fluorescence intensity were compared for slices in the presence and absence of calcium in the external medium for each treatment group. Filledbars denote the values observed in the presence of calcium, and open bars represent the values obtained in calcium-free medium. KruskalWallis one-way ANOVA showed statistically significant differences between the groups $(\mathrm{H}=173.77 ; \mathrm{df}=9 ; p<0.001$; post hoc analysis by Dunn's method was done for comparison of different treatment groups vs controls). Note that treatment with the adenosine $\mathrm{A}_{1}$ agonist $\mathrm{CHA}$ as well as treatment with the $\mathrm{A}_{3}$ agonist $\mathrm{AB}-\mathrm{MECA}$ resulted in increased mobilization of cytosolic calcium regardless of the presence of calcium in the external medium. $B$, Pretreatment of slices with $50 \mu \mathrm{M}$ thapsigargin to deplete internal stores of calcium abolished the response to adenosine $(p<0.01)$. The asterisks describe a significant difference when compared with controls.

the slices with the $\mathrm{A}_{1}$-selective antagonist CPT $(1 \mu \mathrm{M} ; n=58)$. The effect was blocked completely when both CPT $(1 \mu \mathrm{M})$ and the $\mathrm{A}_{3}$-selective antagonist MRS1191 (100 nM; $\left.n=58\right)$ were used (differences between the treatment groups were statistically significant as determined by Kruskal-Wallis nonparametric ANOVA; $\mathrm{H}=97.252$; df $=3$; $p<0.001$ ).

\section{Adenosine-mediated cytosolic calcium increase is caused by release from an intracellular thapsigargin- sensitive calcium store}

Increases in cytoplasmic calcium can be a result of influx of external calcium or release from intracellular stores. To determine whether the increase in cytosolic calcium was a result of influx from the external medium, the calcium orange-loaded slices were treated with adenosine in calcium-free buffer. The increases in cytosolic calcium in response to adenosine, $\mathrm{CHA}$, and $\mathrm{AB}$ MECA in cells stimulated in calcium-free medium were not significantly different from that seen in the presence of calcium in the external medium (illustrated in Fig. 4A; a Kruskal-Wallis one-way ANOVA confirmed the visual impression by a statistically significant difference between the calcium and the no- 


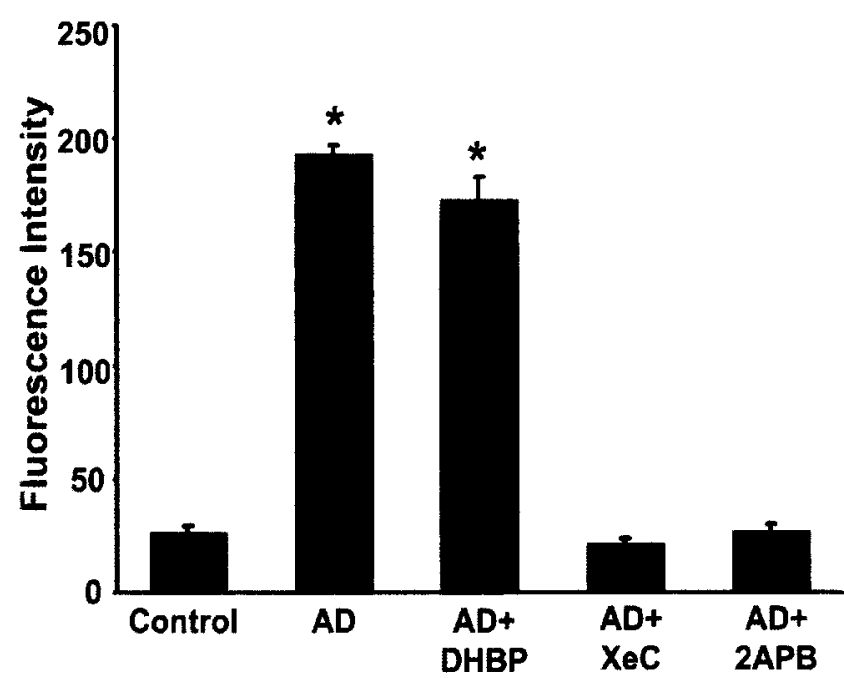

Figure 5. Inhibition of $\mathrm{IP}_{3} \mathrm{R}$ but not RyR blocks the effect of adenosine $(A D)$ on intracellular calcium. A significant increase in intracellular calcium by adenosine $(p<0.01)$ was unaffected when RyR activity was blocked by DHBP. Conversely, blocking the $\mathrm{IP}_{3} \mathrm{R}$ with xestospongin $\mathrm{C}$ $(\mathrm{XeC})$ or $2 \mathrm{APB}$ led to no response to adenosine treatment. The difference between the groups was significant by Kruskal-Wallis one-way ANOVA $(\mathrm{H}=55.864 ; \mathrm{df}=4 ; p<0.001$; Dunn's post hoc analysis was done for multiple comparisons vs controls). The asterisks describe a significant difference when compared with controls.

calcium treatment groups: $\mathrm{H}=173.777 ; \mathrm{df}=9 ; p<0.001)$. This suggested that the source of calcium was from internal stores.

In a separate experiment, depletion of the internal stores by pretreatment of slices with thapsigargin failed to show a calcium response measured after $60 \mathrm{sec}$ of adenosine treatment $(\mathrm{H}=$ 45.987; $\mathrm{df}=2 ; p<0.001$ ) (Fig. $4 B$ ). This also confirmed that the adenosine-mediated increase in cytosolic calcium was a result of mobilization from an internal source.

\section{Adenosine-mediated calcium release from $\mathrm{IP}_{3} \mathrm{R}$ but not RyR regulated intracellular stores}

In neurons, a major source of internal calcium is the stores present in the elaborately distributed network of the ER. Both $\mathrm{IP}_{3} \mathrm{Rs}$ and RyRs distributed throughout the ER are responsible for releasing calcium from this internal source (Kostyuk and Verkhratsky, 1994; Simpson et al., 1995). To determine whether both or either one of these was responsible for the release of internal calcium, we examined the effect of blocking each of those receptors on cytosolic calcium increase in response to adenosine. Three slices per pharmacological agent were pretreated with DHBP $(30 \mu \mathrm{g} / \mathrm{ml}$ ), a potent antagonist of RyRs (Kang et al., 1994); xestospongin $\mathrm{C}(20 \mu \mathrm{M})$, a potent cell-permeable blocker of $\mathrm{IP}_{3} \mathrm{R}$ (Gafni et al., 1997); and 2APB $(50 \mu \mathrm{M})$, a functional and membrane-permeable $\mathrm{IP}_{3} \mathrm{R}$ antagonist (Hamada et al., 1999) for $10 \mathrm{~min}$. The drug treatment alone did not produce any increase in the fluorescence. Blocking of RyR with DHBP $(n=15)$ did not prevent an adenosine-mediated increase in fluorescence, whereas treatment of the slice with either of the $\mathrm{IP}_{3} \mathrm{R}$ blockers (xestospongin $\mathrm{C}, n=26 ; 2 \mathrm{APB}, n=18)$ significantly reduced the increase in fluorescence seen with adenosine $(\mathrm{H}=55.864$; $\mathrm{df}=4$; $p<0.001$ ) (Fig. 5). These results suggested that adenosine mobilizes intracellular calcium primarily via $\mathrm{IP}_{3} \mathrm{Rs}$ and not via RyRs.

\section{DISCUSSION}

The present study demonstrated that adenosine stimulated cytosolic calcium increases in a subpopulation of cholinergic neurons in the BF of rats. This intracellular calcium increase was a result of internal release, primarily via $\mathrm{IP}_{3} \mathrm{Rs}$, in the absence of calcium influx. The response to adenosine was mediated predominantly by $\mathrm{A}_{1}$ receptors, with a smaller but significant contribution by $\mathrm{A}_{3}$ adenosine receptors. Both $\mathrm{A}_{1}$ and $\mathrm{A}_{3}$ receptors are coupled to inhibitory G-proteins. Although there is evidence in the literature for $\mathrm{A}_{3}$ receptor-mediated activation of $\mathrm{IP}_{3}$ production and calcium mobilization in neurons (Abbracchio et al., 1995) and for $\mathrm{A}_{1}$ receptor-mediated calcium signaling in smooth muscle cells and astrocytes (Gerwins and Fredholm, 1992; Biber et al., 1997), this report is the first, to the best of our knowledge, to show $A_{1}$ receptor-mediated mobilization of $\mathrm{IP}_{3}$-regulated intracellular calcium in a subpopulation of cholinergic neurons in the BF.

Our data demonstrated that adenosine induced a relatively slow release of intracellular calcium from internal calcium stores and that it occurred at higher concentrations of adenosine. The time course of calcium increase was similar to that in other reports on PLC-linked G-protein-coupled receptors, such as metabotropic glutamate receptor 5 and the angiotensin II receptor (Ceolotto et al., 2001; Nash et al., 2001). The fact that $\mathrm{IP}_{3}$-dependent mobilization of intracellular calcium is dependent on a high concentration of adenosine, similar to what has been described in astrocytes by Biber et al. (1997), supports the notion that increased agonist, and a consequently higher number of stimulated receptors, would release a larger number of G-protein $\beta \gamma$ subunits and thus potentiate the activation of PLC (Camps et al., 1992). Recently, G-protein $\beta \gamma$ subunit-mediated activation of PLC and a subsequent increase in cytosolic calcium caused by release from internal stores has been reported for $\mathrm{G}_{1}$-coupled dopamine $\mathrm{D}_{2}$ receptors in the striatum (Hernández-López et al., 2000). In neurons, the ER contributes significantly to the dynamics of calcium signaling by acting as either a source or a sink of calcium (Simpson et al., 1995; Berridge, 1998, 2000). Both $\mathrm{IP}_{3} \mathrm{Rs}$ and RyRs are widely distributed in brain ER and can influence the release of internal calcium (McPherson et al., 1991; SeymourLaurent and Barish, 1995). Our results strongly suggest that adenosine-dependent calcium increase in cholinergic neurons is mediated via $\mathrm{IP}_{3}$ Rs.

\section{Calcium mobilization in cholinergic neurons of the BF}

The selectivity of adenosine-induced calcium mobilization in cholinergic neurons is of interest in disambiguating the roles of different neurotransmitter phenotypes in the BF. That the increase in intracellular calcium fluorescence was always in cholinergic neurons suggested a selective functional recruitment of a subpopulation of cholinergic neurons in the BF. Recently, selective actions of galanin on cholinergic versus noncholinergic neurons in the HDB of the BF have been noted (Jhamandas et al., 2002). The cholinergic neurons examined in this study belong to part of the HDB, SI, and MCPO. These cholinergic neurons target both the neocortex and amygdala and regulate aspects of arousal, cognition, attention, and emotion (Szymusiak, 1995; Semba, 2000). Several approaches toward disentangling the anatomy of the cholinergic subpopulations have been adopted; for example, neurochemical distinctions may be based on the immunohistochemical studies for the coexpression of several neuropeptides (for review, see Semba, 2000). Recently, a functional correlation based on the firing pattern of cholinergic neurons was used to determine the projections to the retrosplenial or prefron- 
tal cortex in separate sets of cholinergic neurons in the $\mathrm{BF}$ (Manns et al., 2000). Our data point to a large population (65\%) of cholinergic neurons with a unique biochemical response to adenosine of calcium mobilization from internal stores.

An interesting question is the possible mechanism(s) by which the adenosine receptor, particularly the $A_{1}$ receptor, known for its wide presence on all types of cells, exhibits a selective biochemical response in cholinergic neurons. Site- and contextspecific differential activation of G-protein-coupled receptors has been posited to occur as a result of different molecular interactions, either by homodimerization-heterodimerization or interactions with accessory proteins to influence the activity of the receptor (for review, see Bouvier, 2001). In particular, $A_{1}$ adenosine receptor function can be influenced by a homodimer (Ciruela et al., 1995), by a heterodimer (Gines et al., 2000; Ciruela et al., 2001), and by interaction with ectoadenosine deaminase (Franco et al., 1997).

We suggest that it is unlikely that the selectivity to cholinergic neurons is artifactual. The fact that thapsigargin treatment could elicit similar responses in all types of cells strongly supports our suggestion. Notably, our data also show that the dye calcium orange might be particularly useful for subsequent immunochemistry to identify the responding cholinergic neurons. This feature of calcium orange most likely relates to its high photostability and membrane impermeability after de-esterification in cytoplasm (Eberhard and Erne, 1991; Thomas et al., 2000). Our results suggested that calcium orange retains its place within the neuron even after fixation with formalin as a fixative. We observed that calcium orange-loaded neurons could be fixed without apparent leak of fluorescence outside the cells, because there was no "aura" around neurons and no increase in background after 1 and $24 \mathrm{hr}$ of formalin treatment. Similar observations have been reported for another fluorescent dye, Lucifer yellow (Stewart, 1978). Moreover, fixation of the slices also did not alter the fluorescence inside the cells, because the adenosine-induced increase in fluorescence after fixation was the same as that observed in real time. Similar results were obtained in calcium orange-loaded cultured HEK 293 cells, in which cytosolic calcium fluorescence intensity remained stable, without any leak into the medium, after fixation with formalin (data not shown).

\section{Calcium signaling and transcription}

Calcium signals induce gene expression that may be important for long-lasting adaptations (Bading, 2000; Mattson et al., 2000; Mellström and Naranjo, 2001). Such a role for calcium is well described in the nervous system, in which transient changes in intracellular calcium can produce distinct transcriptional responses (Bading et al., 1993; Ghosh and Greenberg, 1995). Calcium changes also regulate the transcription factor NF- $\kappa \mathrm{B}$ (Dolmetsch et al., 1998). We have reported previously that adenosine treatment of brain slices resulted in nuclear translocation of $\mathrm{NF}-\kappa \mathrm{B}$ in the BF, a phenomenon also observed after $3 \mathrm{hr}$ of sleep deprivation (Basheer et al., 2001a). Together, these observations support the idea that increased levels of extracellular adenosine (as present with sleep deprivation) may preferentially activate the PLC pathway to mobilize internal calcium, then activate PKC, which is shown to induce nuclear translocation of $\mathrm{NF}-\kappa \mathrm{B}$ in lymphocytes (Nishizuka, 1992; Finco and Baldwin, 1995).

\section{A link between sleep deprivation-induced adenosine increase and NF- $\kappa \mathrm{B}$ activation}

The behavioral significance of these results may be best understood in the context of sleep deprivation and its long-term effects.
Our previous reports showed a unique pattern of sleep deprivation-induced increases in extracellular adenosine as well as its effect on $A_{1}$ adenosine receptor activation of transcription factor NF- $\kappa$ B in the BF (Porkka-Heiskanen et al., 1997, 2000; Basheer et al., 2000, 2001a). One of the questions generated from those studies was the identity of the signal transduction pathway linking the increased levels of extracellular adenosine with the PKC-dependent induction of NF- $\kappa \mathrm{B}$ (Finco and Baldwin, 1995). Our results have provided evidence that adenosine can mobilize $\mathrm{IP}_{3}$-regulated intracellular calcium, which may help the activation of NF- $\kappa$ B. NF- $\kappa \mathrm{B}$, in turn, may be involved in the expression of genes, including that of the $A_{1}$ receptor, which is upregulated with sleep deprivation (Basheer et al., 2001b) and which may play a role in mediating the longer-term effects of sleep deprivation.

Finally, we believe that these observations help in understanding the complex organization of the BF by providing a biochemical distinction for a major subgroup of cholinergic neurons; these neurons may play a specific role in mediating some of the longerterm effects of sleep deprivation-induced adenosine in the BF.

\section{REFERENCES}

Abbracchio MP, Brambilla R, Ceruti S, Kim HO, von Lubitz DK, Jacobson KA, Cattabeni F (1995) G protein-dependent activation of phospholipase $\mathrm{C}$ by adenosine A3 receptors in rat brain. Mol Pharmacol 48:1038-1045.

Bading H (2000) Transcription-dependent neuronal plasticity: the nuclear calcium hypothesis. Eur J Biochem 267:5280-5283.

Bading H, Ginty DD, Greenberg ME (1993) Regulation of gene expression in hippocampal neurons by distinct calcium signaling pathways. Science 260:181-186.

Basheer R, Porkka-Heiskanen T, Stenberg D, McCarley RW (1999) Adenosine and behavioral state control: adenosine increases c-Fos protein and AP1 binding in basal forebrain of rats. Brain Res Mol Brain Res 73:1-10.

Basheer R, Porkka-Heiskanen T, Strecker RE, Thakkar MM, McCarley RW (2000) Adenosine as a biological signal mediating sleepiness following prolonged wakefulness. Biol Signals Recept 9:319-327.

Basheer R, Rainnie DG, Porkka-Heiskanen T, Ramesh V, McCarley RW (2001a) Adenosine, prolonged wakefulness, and A1-activated NF- $\kappa$ B DNA binding in the basal forebrain of the rat. Neuroscience 104:731-739.

Basheer R, Halldner L, Alanko L, McCarley RW, Fredholm BB, PorkkaHeiskanen $T$ (2001b) Opposite changes in adenosine $A_{1}$ and $A_{2 A}$ receptor mRNA in the rat following sleep deprivation. NeuroReport $12: 1577-1580$.

Berridge MJ (1998) Neuronal calcium signaling. Neuron 21:13-26.

Berridge MJ, Lipp P, Bootman MD (2000) The versatility and universality of calcium signalling. Nat Rev Mol Cell Biol 1:11-21.

Biber K, Klotz KN, Berger M, Gebicke-Harter PJ, van Calker D (1997) Adenosine $A_{1}$ receptor-mediated activation of phospholipase $C$ in cultured astrocytes depends on the level of receptor expression. J Neurosci 17:4956-4964.

Bouvier M (2001) Oligomerization of G-protein-coupled transmitter receptors. Nat Rev Neurosci 2:274-286.

Camps M, Carozzi A, Schnabel P, Scheer A, Parker PJ, Gierschik P (1992) Isozyme-selective stimulation of phospholipase C- $\beta 2$ by $G$ protein $\beta \gamma$-subunits. Nature 360:684-686.

Ceolotto G, Valente R, Baritono E, Reato S, Iori E, Monari A, Trevisan $\mathrm{R}$, Semplicini A (2001) Effect of insulin and angiotensin II on cell calcium in human skin fibroblasts. Hypertension 37:1486-1491.

Ciruela F, Casado V, Mallol J, Canela EI, Lluis C, Franco R (1995) Immunological identification of $\mathrm{A}_{1}$ adenosine receptors in brain cortex. J Neurosci Res 42:818-828.

Ciruela F, Escriche M, Burgueño J, Angulo E, Casado V, Soloviev MM, Canela EI, Mallol J, Chan W-Y, Lluis L, McIlhinney JRA, Franco R (2001) Metabotropic glutamate $1 \alpha$ and adenosine $A_{1}$ receptors assemble into functionally interacting complexes. J Biol Chem 276:18345-18351.

Denk W, Piston DW, Webb W (1995) Two photon molecular excitation in laser scanning microscopy. In: Handbook of biological confocal microscopy, Ed 2 (Pawley J, ed), pp 445-458. New York: Plenum.

Dinges DF, Douglas SD, Hamarman S, Zaugg L, Kapoor S (1995) Sleep deprivation and human immune function. Adv Neuroimmunol 5:97-110.

Dinges DF, Pack F, Williams K, Gillen KA, Powell JW, Ott GE, Aptowicz C, Pack AI (1997) Cumulative sleepiness, mood disturbance, and 
psychomotor vigilance performance decrements during a week of sleep restricted to 4-5 hours per night. Sleep 20:267.

Dolmetsch RE, Lewis RS, Goodnow CC, Healy JI (1998) Differential activation of transcription factors induced by $\mathrm{Ca}^{2+}$ response amplitude and duration. Nature 386:759-760.

Drummond SP, Brown GG, Gillin JC, Stricker JL, Wong EC, Buxton RB (2000) Altered brain response to verbal learning following sleep deprivation. Nature 403:655-657.

Duffy S, MacVicar BA (1996) In vitro ischemia promotes calcium influx and intracellular calcium release in hippocampal astrocytes. J Neurosci 16:71-81.

Eberhard M, Erne P (1991) Calcium binding to fluorescent calcium indicators: calcium green, calcium orange, and calcium crimson. Biochem Biophys Res Commun 180:209-215.

Finco TS, Baldwin AS (1995) Mechanistic aspects of NF- $\kappa$ B regulation: the emerging role of phosphorylation and proteolysis. Immunity 3:263-272.

Franco R, Casadò V, Ciruela F, Saura C, Mallol J, Canela EI, Lluis C (1997) Cell surface adenosine deaminase: much more than an ectoenzyme. Prog Neurobiol 52:283-294.

Gafni J, Munsch JA, Lam TH, Catlin MC, Costa LG, Molinski TF, Pessah IN (1997) Xestospongins: potent membrane permeable blockers of the inositol 1,4,5-trisphosphate receptor. Neuron 19:723-733.

Gerwins P, Fredholm BB (1992) ATP and its metabolite adenosine act synergistically to mobilize intracellular calcium via the formation of inositol 1,4,5-trisphosphate in a smooth muscle cell line. J Biol Chem 267:16081-16087.

Ghosh A, Greenberg ME (1995) Calcium signaling in neurons: molecular mechanisms and cellular consequences. Science 268:239-247.

Gines S, Hillion J, Torvinen M, Le Crom S, Casado V, Canela EI, Rondin S, Lew JY, Watson S, Zoli M, Agnati LF, Verniera P, Lluis C, Ferre S, Fuxe K, Franco R (2000) Dopamine $D_{1}$ and adenosine $A_{1}$ receptors form functionally interacting heteromeric complexes. Proc Natl Acad Sci USA 97:8606-8611.

Gritti I, Mainville L, Jones BE (1993) Codistribution of GABA- with acetylcholine-synthesizing neurons in the basal forebrain of the rat. J Comp Neurol 329:438-457.

Gudermann T, Kalkbrenner F, Schultz G (1996) Diversity and selectivity of receptor-G protein interaction. Annu Rev Pharmacol Toxicol 36:429-459.

Gudermann T, Schoneberg T, Schultz G (1997) Functional and structural complexity of signal transduction via G-protein-coupled receptors. Annu Rev Neurosci 20:399-427.

Haas HL, Selbach O (2000) Functions of neuronal adenosine receptors. Naunyn Schmiedebergs Arch Pharmacol 362:375-381.

Hamada T, Liou SY, Fukushima T, Maruyama T, Watanabe S, Mikoshiba $\mathrm{K}$, Ishida $\mathrm{N}$ (1999) The role of inositol trisphosphate-induced $\mathrm{Ca}^{2+}$ release from $\mathrm{IP}_{3}$-receptor in the rat suprachiasmatic nucleus on circadian entrainment mechanism. Neurosci Lett 263:125-128.

Hardingham GE, Bading H (1999) Calcium as a versatile second messenger in the control of gene expression. Microsc Res Tech 46:348-355.

Hernández-López S, Tkatch T, Perez-Garci E, Galarraga E, Bargas J, Hamm H, Surmeier JD (2000) $\mathrm{D}_{2}$ dopamine receptors in striatal medium spiny neurons reduce L-type $\mathrm{Ca}^{2+}$ currents and excitability via a novel PLC $\beta 1-\mathrm{IP}_{3}$-calcineurin signaling cascade. $\mathrm{J}$ Neurosci 20:8987-8995.

Jhamandas JH, Harris KH, MacTavish D, Jassar BS (2002) Novel excitatory actions of galanin on rat cholinergic basal forebrain neurons: implications for its role in Alzheimer's disease. J Neurophysiol 87:696-704.

Kang JJ, Hsu KS, Lin-Shiau SY (1994) Effects of bipyridylium com- pounds on calcium release from triadic vesicles isolated from rabbit skeletal muscle. Br J Pharmacol 112:1216-1222.

Klotz KN (2000) Adenosine receptors and their ligands. Naunyn Schmiedebergs Arch Pharmacol 362:382-391.

Kostyuk P, Verkhratsky A (1994) Calcium stores in neurons and glia. Neuroscience 63:381-404.

Manns ID, Alonso A, Jones BE (2000) Discharge properties of juxtacellularly labeled and immunohistochemically identified cholinergic basal forebrain neurons recorded in association with the electroencephalogram in anesthetized rats. J Neurosci 20:1505-1518.

Mattson MP, LaFerla FM, Chan SL, Leissring MA, Shepel PN, Geiger JD (2000) Calcium signaling in the ER: its role in neuronal plasticity and neurodegenerative disorders. Trends Neurosci 23:222-229.

McKinsey TA, Chu ZL, Ballard DW (1997) Phosphorylation of the PEST domain of $\mathrm{I} \kappa \mathrm{B} \beta$ regulates the function of $\mathrm{NF}-\kappa \mathrm{B} / \mathrm{I} \kappa \mathrm{B} \beta$ complexes. J Biol Chem 272:22377-22380.

McPherson PS, Kim YK, Valdivia H, Knudson CM, Takekura H, Franzini-Armstrong C, Coronado R, Campbell KP (1991) The brain ryanodine receptor: a caffeine-sensitive calcium release channel. Neuron $7: 17-25$.

Mellström B, Naranjo JR (2001) Mechanisms of $\mathrm{Ca}^{2+}$-dependent transcription. Curr Opin Neurobiol 11:312-319.

Nash MS, Young KW, Challiss RA, Nahorski SR (2001) Intracellular signalling: receptor-specific messenger oscillations. Nature 413:381-382.

Nishizuka Y (1992) Intracellular signaling by hydrolysis of phospholipids and activation of protein kinase C. Science 258:607-614.

Paxinos G, Watson C (1998) The rat brain in stereotaxic coordinates. New York: Academic.

Porkka-Heiskanen T, Strecker RE, Thakkar M, Bjorkum AA, Greene RW, McCarley RW (1997) Adenosine: a mediator of the sleepinducing effects of prolonged wakefulness. Science 276:1265-1268.

Porkka-Heiskanen T, Strecker RE, McCarley RW (2000) Brain sitespecificity of extracellular adenosine concentration changes during sleep deprivation and spontaneous sleep: an in vivo microdialysis study. Neuroscience 99:507-517.

Rainnie DG, Grunze HC, McCarley RW, Greene RW (1994) Adenosine inhibition of mesopontine cholinergic neurons: implications for EEG arousal. Science 263:689-692.

Semba K (2000) Multiple output pathways of the basal forebrain: organization, chemical heterogeneity, and roles in vigilance. Behav Brain Res 115:117-141.

Seymour-Laurent KJ, Barish ME (1995) Inositol 1,4,5-trisphosphate and ryanodine receptor distributions and patterns of acetylcholine- and caffeine-induced calcium release in cultured mouse hippocampal neurons. J Neurosci 15:2592-2608.

Simpson PB, Challiss RA, Nahorski SR (1995) Neuronal $\mathrm{Ca}^{2+}$ stores: activation and function. Trends Neurosci 18:299-306.

Spiegel K, Leproult R, Van Cauter E (1999) Impact of sleep debt on metabolic and endocrine function. Lancet 354:1435-1439.

Stewart WW (1978) Functional connections between cells as revealed by dye-coupling with a highly fluorescent naphthalimide tracer. Cell 14:741-759.

Szymusiak R (1995) Magnocellular nuclei of the basal forebrain: substrates of sleep and arousal regulation. Sleep 18:478-500.

Thomas D, Tovey SC, Collins TJ, Bootman MD, Berridge MJ, Lipp P (2000) A comparison of fluorescent $\mathrm{Ca}^{2+}$ indicator properties and their use in measuring elementary and global $\mathrm{Ca}^{2+}$ signals. Cell $\mathrm{Cal}-$ cium 28:213-223.

Zaborszky L, Pang K, Somogyi J, Nadasdy Z, Kallo I (1999) The basal forebrain corticopetal system revisited. Ann NY Acad Sci 877:339-367. 